\title{
Visualization Modeling of Networks Management Systems
}

\author{
Lubomyr Petryshyn \\ dept. of Enterprise Management \\ AGH University of Science \\ and Technology \\ Cracow, Poland \\ 1.b.petryshyn@gmail.com ORCID: 0000- \\ 0003-4168-3891
}

\author{
Wioleta Cieslik \\ dept. of Computer Science \\ AGH University of Science \\ and Technology \\ Cracow, Poland \\ w.cieslik@gmail.com
}

\author{
Mykhailo Petryshyn \\ dept. of Computer Science \\ and Information Systems \\ Precarpathian National University \\ Ivano-Frankivsk, Ukraine \\ m.l.petryshyn@gmail.com \\ ORCID: 0000-0001-6319-3768
}

\section{Wizualizacyjne Modelowanie Sieciowych Systemów Zarządzania}

\author{
Lubomyr Petryshyn \\ kat. Zarządzania Przedsiębiorstwem \\ AGH University of Science \\ and Technology \\ Kraków, Polska \\ 1.b.petryshyn@gmail.com ORCID: 0000- \\ 0003-4168-3891
}

\author{
Wioleta Cieślik \\ kat. Informatyki Stosowanej \\ AGH University of Science \\ and Technology \\ Kraków, Polska \\ w.cieslik@gmail.com
}

\author{
Mykhailo Petryshyn \\ kat. Nauk Komputerowych \\ i Systemów Informatycznych \\ Precarpathian National University \\ Ivano-Frankivsk, Ukraina \\ m.l.petryshyn@gmail.com \\ ORCID: 0000-0001-6319-3768
}

\begin{abstract}
Adnotacja-Modelowanie procesów zarządzania w warunkach kooperacji sektorowej na podstawie rozproszonych systemów informatycznych pozwala zmniejszyć koszty opracowania i eksploatacji takich zlożonych systemów. Proponowana metoda wizualizacji modeli informacyjnych pozwala na odwzorowanie $w$ formie graficznej procesów $i$ upraszcza porozumienie się na etapie analizy i projektowania pomiędzy zleceniodawcą a producentem systemu. Przedstawiono podstawy modelowania wizualizacyjnego i uproszczony przykład opracowania systemu wielosektorowego zarządzania siecią dostaw produkcji.
\end{abstract}

Stowa kluczowe-modelowanie wizualizacyjne, procesy informacyjne, kooperacja sektorowa, systemy rozproszone, zarzadzanie

Abstract-Simulation of the processes of sectoral cooperation management in distributed information systems allows to reduce the means of introduction and operation of such complex systems. The proposed method of visualization of information models reflects graphically the constituent processes and simplifies the understanding at the stage of analysis and design between the customer and the system developer. The basics of visualization modeling and simplified example of models development of multi-sectoral management system are presented.

Keywords-visualization modeling, information processes, sectoral cooperation, distributed systems, management

\section{WSTĘP}

Zarządzanie złożonymi systemami w warunkach kooperacji sektorowej wymaga zastosowania technologii informacyjnej, która zapewnia odwzorowanie stanu i umożliwia zarządzanie systemem w czasie rzeczywistym. Opracowany materiał jest zintegrowaną częścią publikacji [1], która przedstawia technikę analizy procesowej w zarządzaniu, będącej $\mathrm{z}$ kolei podstawą modelowania informacyjnego. Wizualizacja procesów zarządzania pozwala na usunięcie bariery psychologicznej i uniknięcie nieporozumienia pomiędzy klientem i twórcą systemów informatycznych, a także pozwala zmniejszyć koszty opracowania, wdrażania i obsługi takich złożonych systemów.

Celem opracowania jest przedstawienie wizualnych metod modelowania procesów zarządzania złożonymi systemami w warunkach kooperacji sektorowej, a także opracowanie uproszczonego przykładu systemu zarządzania firmą.

Nowacją pracy jest opracowanie i przedstawienie graficznych metod modelowania, które zapewniają wizualizację procesów zarządzania i upraszczają zrozumienie ich przepływu.

Aspekt praktyczny polega na możliwości odwzorowania struktury i przepływu procesów zarządzania, unikania nieporozumień przy formułowaniu zadania i zapewniania wymagań klienta, a także zmniejszania kosztów tworzenia i eksploatacji systemów zarządzania.

Podstawy modelowania wizualizacyjnego są opublikowane w [2]. Przeanalizujemy uproszczony przykład modelowania rozproszonego systemu zarządzania siecią sprzedaży produkcji z punktów gastronomicznych $\mathrm{w}$ skali kraju w celu usprawnienia i ułatwienia potencjalnemu klientowi wyboru konkretnego zamówienia wg jego potrzeb 
w danej chwili. Innym aspektem jest wypromowanie początkujące punktów gastronomicznych i poszerzenie oferty sprzedażowej tych, które już prosperują na rynku. Na podstawie analizy procesowej oraz dekompozycji systemu zarządzania [1] przeprowadzimy modelowanie informacyjne systemu.

\section{Modelowanie Procesów ZarZĄDZANIA}

System zarządzania pozostał zdekomponowany na następujące jednostki organizacyjno-strukturalne: M1 - dział zamówienia; M2 - dział dostaw; M3 - dział finansów; M4 dział marketingu; M5 - dział sprzedaż; M6 - dział analityczny; M7 - dział obsługi klienta (support); M8 - dział zniżek.

Wynikiem dekompozycji procesów systemu zarządzania [1] jest definicja następujących operacji systemowych:

D1.M1 - Zarejestrowanie zamówienia w systemie;

D1.M4-Sprawdzenie czy trwa aktualnie kampania promocyjna na wybrany przez klienta produkt;

D1.M8 - Sprawdzenie czy dany klient jest uprawniony do rabatu i automatyczne przyznanie mu go;

D2.M1 - Otrzymanie informacji zwrotnej;

D3.M3 - Zaksięgowanie transakcji;

D3.M5 - Przesłanie zamówienia do punktu gastronomicznego, z którego klient wybrał zamówienie;

D3.M6 - Przesłanie danych do analizy;

D4.M1 - Otrzymanie informacji od punktu gastronomicznego;

D5.M2 - Powiadomienie klienta o czasie trwania dostawy;

D6.M4 - Opracowanie strategii promocyjnej;

D7.M1 - Ujęcie promocyjnych cen w systemie;

D8.M3 - Udokumentowanie promocji;

D9.M6 - Zebranie wyników do analiz w czasie trwania promocji i ocena promocji;

D10.M7 - Informacja od klienta o nieprawidłowości zamówienia;

D11.M1 - Zaksięgowanie reklamacji w systemie;

D12.M5 - Poinformowanie punktu gastronomicznego;

D13.M1 - Informacja zwrotna z punktu gastronomicznego o uznaniu reklamacji;

D14.M7 - Informacja do klienta o uznaniu reklamacji.

Wymienione operacje systemowe są uporządkowane $\mathrm{w}$ procesie zarządzania wg następujących modelów graficznych.

\section{A. Model matrycowy}

Model matrycowy procesu zarządzania całego systemu zawiera trzy podprocesy (rys. 2): realizację zamówienia, promocję i złożenie zażalenia przez klienta (przypadek uznania). Taki model pozwala na wizualizację postępu realizacji operacji systemowych w procesach przedsiębiorstwa, wykonywanych w odpowiednich jednostkach w skali czasu.

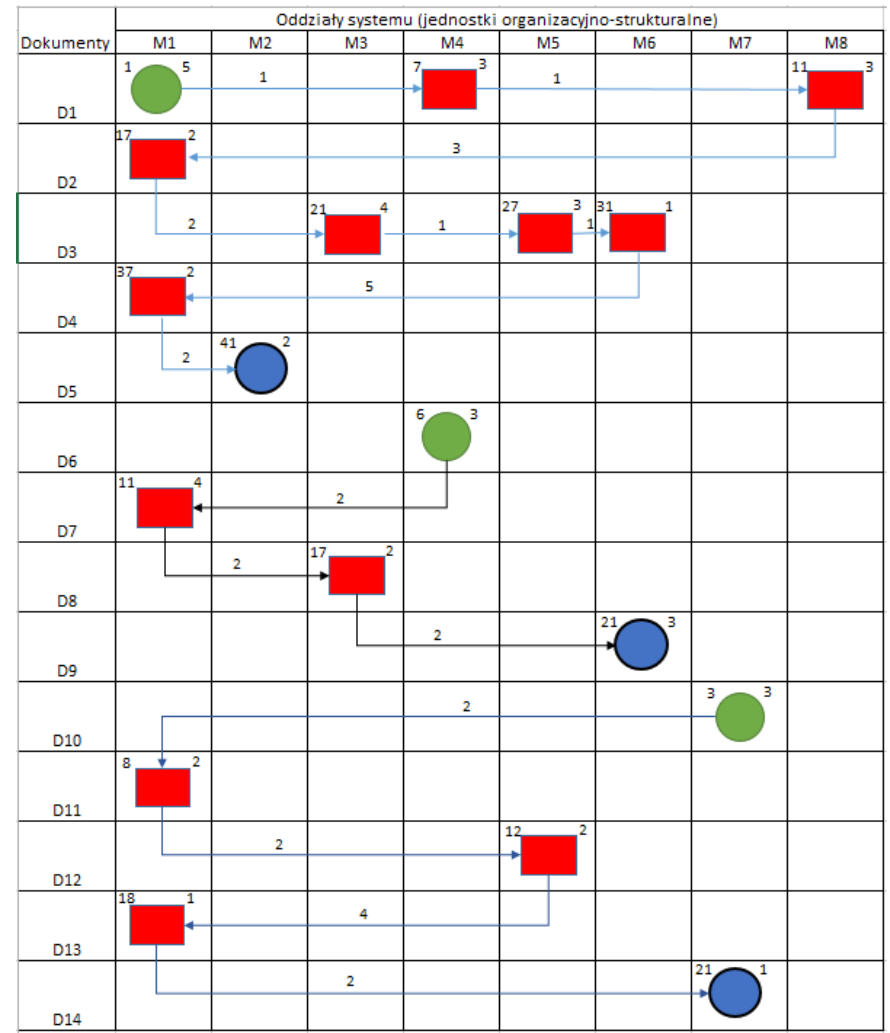

Rys. 1. Model matrycowy systemu zarządzania.

Na rys. 2: - źródło informacji; - przetwarzanie informacji; $\bigcirc$ - odbiór informacji.

\section{B. Tablice czasowe}

Tablice czasowe zawierają czasy rozpoczęcia, formowania, przetwarzania oraz ustalenia przetwarzania oraz przepływów operacji systemowych.

Tablice czasowe określają rozkład w skali czasu poszczególnych operacji systemowych procesów. Tabl. I przedstawia czasy rozpoczęcia, tworzenia, przetwarzania i ustalania operacji systemowych. Natomiast tabl. II pokazuje czasy przekazania dokumentów przy wykonaniu operacji systemowych.

\section{Model ,graf sieciowy”}

Model graf sieciowy (rys. 3) jest podstawowym modelem, który umożliwia przejście do UML-modelowania i przedstawia podstawowe parametry systemu takie jak struktura, czas rozpoczęcia i trwania operacji systemowych oraz połączenie kanałów komunikacyjnych.

\section{Model czasowy spójny}

Aby ocenić pełne obciążenie obliczeniowe informatycznego systemu zarządzania stosuję się spójny model czasowy (rys.4). Graf ten jednak nie uwzględnia działów, w jakich wykonują się poszczególne operacje systemowe. 
TABLICA I. CZASY WYKONANIA OPERACJI SYSTEMOWYCH

\begin{tabular}{|c|c|c|c|c|}
\hline \multirow[b]{2}{*}{ Dokumenty } & \multicolumn{4}{|c|}{ Czas } \\
\hline & Rozpoczęcia & Formowania & $\begin{array}{c}\text { Przetwa- } \\
\text { rzania }\end{array}$ & Ustalania \\
\hline D1.M1 & 1 & 5 & & \\
\hline \multirow[t]{2}{*}{ D6.M4 } & & & & \\
\hline & 6 & 3 & & \\
\hline D10.M7 & 3 & 3 & & \\
\hline D1.M4 & 7 & & 3 & \\
\hline D1.M8 & 11 & & 3 & \\
\hline D2.M1 & 17 & & 2 & \\
\hline D3.M3 & 21 & & 4 & \\
\hline D3.M5 & 27 & & 3 & \\
\hline D3.M6 & 31 & & 1 & \\
\hline D4.M1 & 37 & & 2 & \\
\hline D7.M1 & 11 & & 4 & \\
\hline D8.M3 & 17 & & 2 & \\
\hline D11.M1 & 8 & & 2 & \\
\hline D12.M5 & 12 & & 2 & \\
\hline D13.M1 & 18 & & 1 & \\
\hline D5.M2 & 41 & & & 2 \\
\hline D9.M6 & 21 & & & 3 \\
\hline D14.M6 & 21 & & & 1 \\
\hline
\end{tabular}

TABLICA II. CZASY PRZEKAZANIA DOKUMENTÓW W SYSTEMIE PRZY WYKONANIU OPERACJI SYSTEMOWYCH

\begin{tabular}{|c|c|}
\hline Dokumenty & Czas przekazania \\
\hline D1.M1-D1.M4 & 1 \\
\hline D1.M4- D1.M8 & 1 \\
\hline D1.M8 - D2.M1 & 3 \\
\hline D2.M1 - D3.M3 & 2 \\
\hline D3.M3 - D3.M5 & 1 \\
\hline D3.M5 - D3.M6 & 1 \\
\hline D3.M6 - D4.M1 & 5 \\
\hline D4.M1 - D5.M2 & 2 \\
\hline D6.M4 - D7.M1 & 2 \\
\hline D7.M1 - D8.M3 & 2 \\
\hline D8.M3 - D9.M6 & 2 \\
\hline D10.M7 - D11.M1 & 2 \\
\hline D11.M1 - D12.M5 & 2 \\
\hline D12.M5 - D13.M1 & 4 \\
\hline D13.M1 - D14.M7 & 2 \\
\hline
\end{tabular}

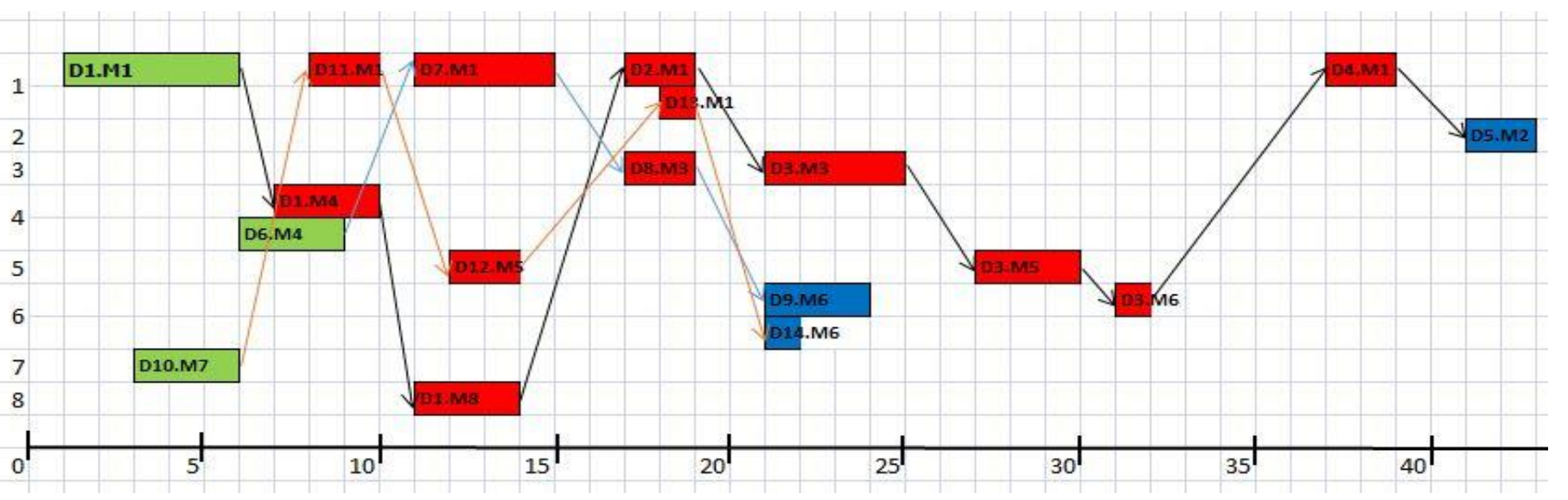

Rys. 2. Model ,graf sieciowy” (typu Gantta).

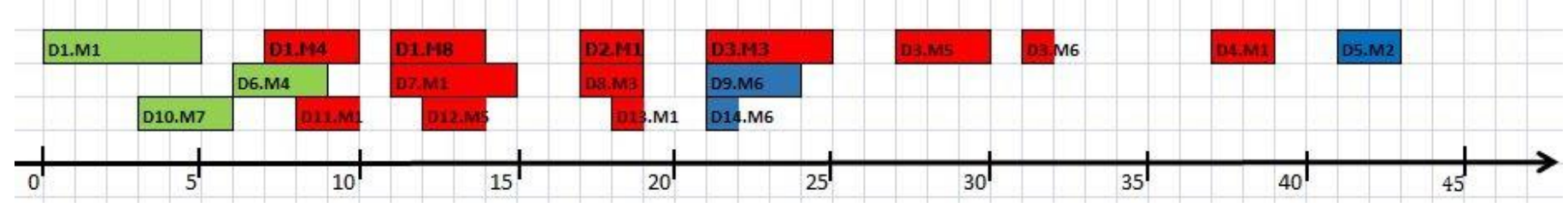

Rys. 3. Model czasowy spójny wykonania operacji systemowych.

E. Schemat btokowy algorytmu wykonania operacji systemowych

$\mathrm{Na}$ podstawie modelu spójnego wykresu czasowego pozostał opracowany schemat blokowy algorytmu programu

wykonania operacji systemowych (rys. 5), który na podstawie programowania obiektowego umożliwia szybką implementację i wdrożenie oprogramowania aplikacyjnego. 


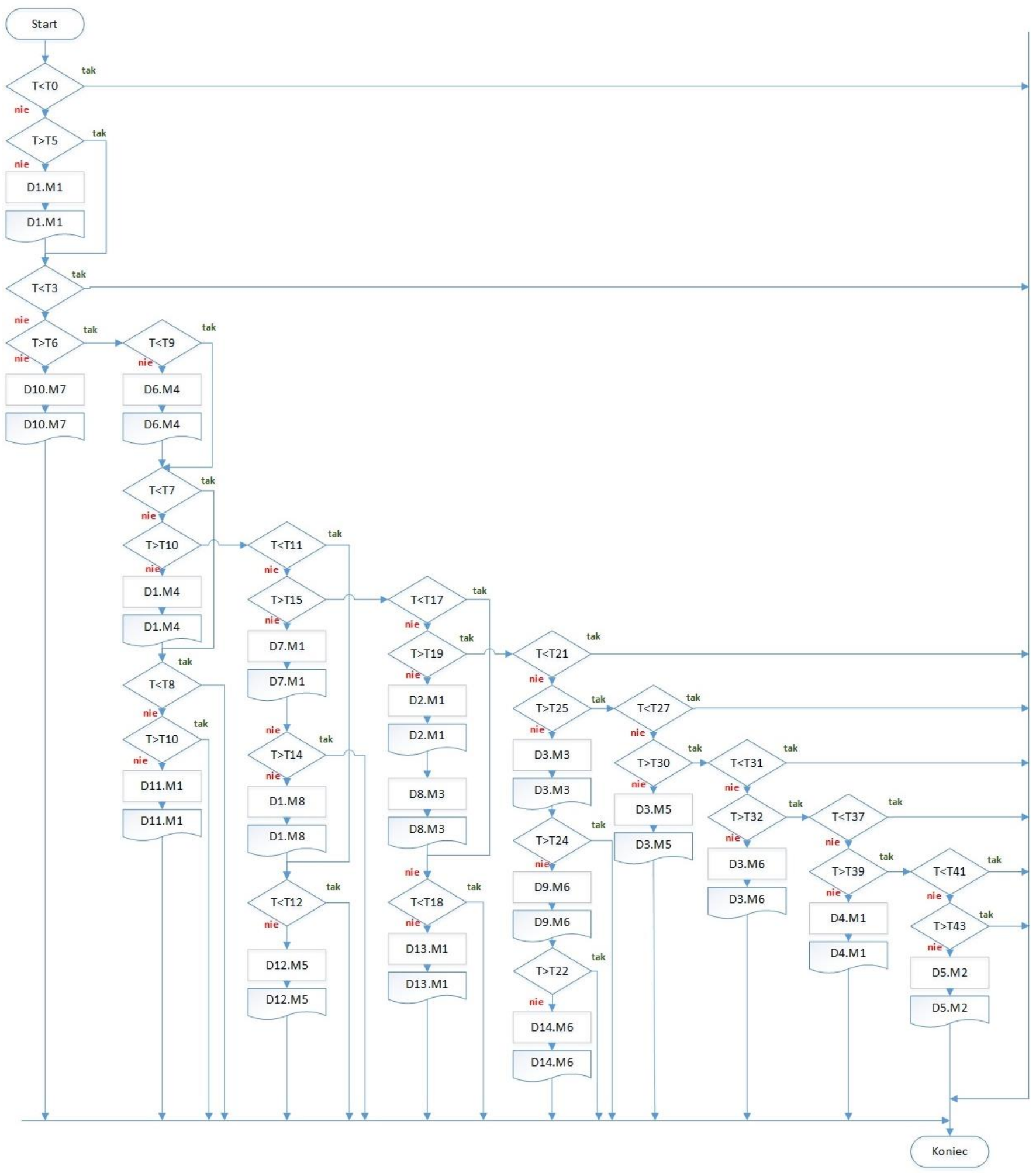

Rys. 4. Schemat blokowy algorytmu wykonania operacji systemowych. 
III. SYMULACJA PROCESÓW W MODELOWANYM SYSTEMIE

Symulację procesową przeprowadzono za pomocą online programu BPSimulator, znajdującego się na stronie http://www.bpsimulator.com [2]. Poniżej znajduje się model użyty do symulacji (rys. 6) oraz raport $\mathrm{z}$ niego wygenerowany (rys. 7). Symulacja pozwoliła oszacować koszty systemu i pokazać średni czas realizacji każdego procesu.

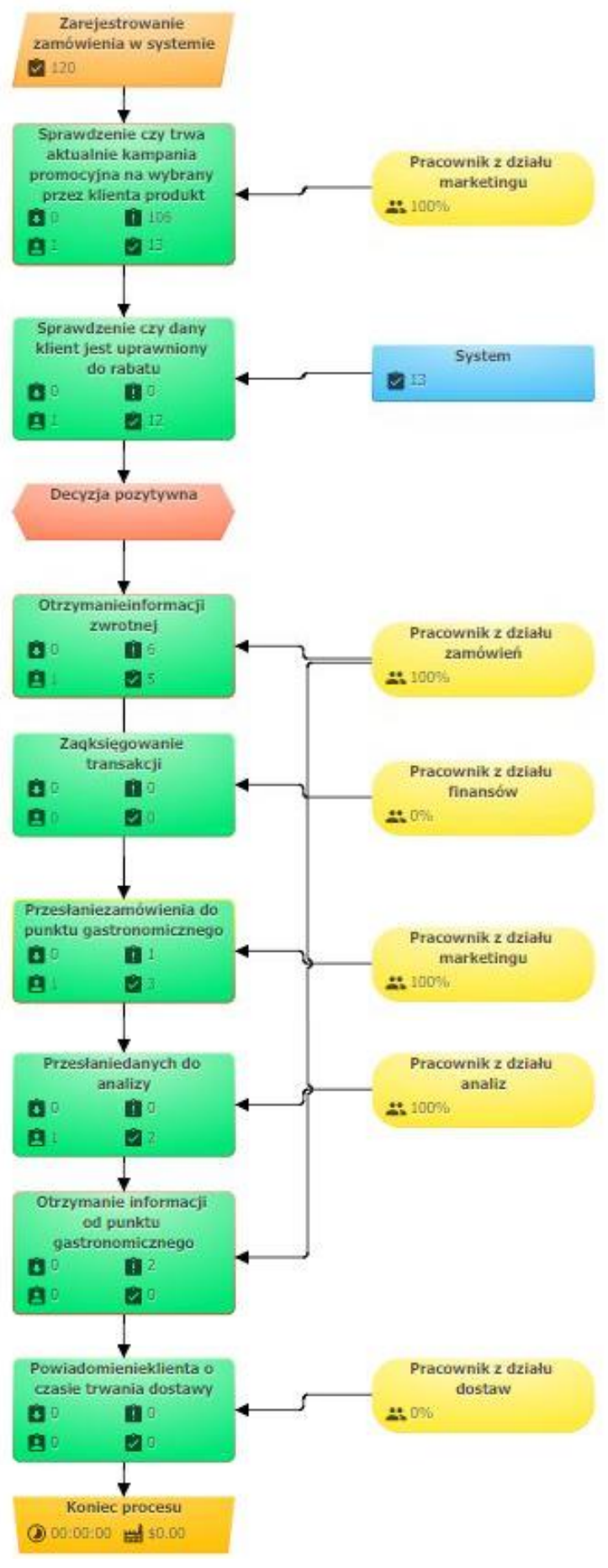

Rys. 5. . Model symulacji systemu zarządzania.
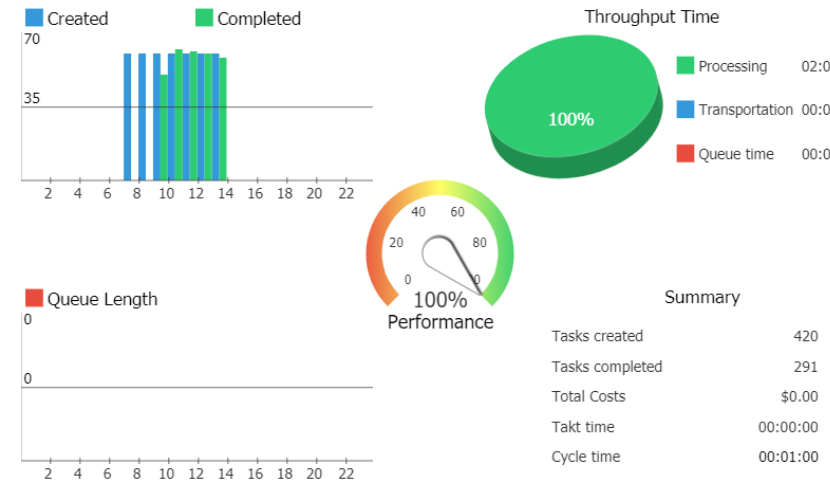

Rys. 6. Raport symulacji obciążenia informatycznego systemu zarządzania.

\section{PODSUMOWANIE}

W oparciu o opracowane metody wizualizacji przebiegu funkcjonowania złożonych systemów zarządzania w warunkach kooperacji sektorowej określono podstawy symulacji, które pozwoliły na prezentacje przebiegu procesów i umożliwiły zarządzanie systemem informacyjnym w czasie rzeczywistym. Wizualizacja procesów zarządzania pozwoliła usunąć barierę psychologiczną i uniknąć wzajemnego nieporozumienia między klientem a twórcą systemów informatycznych a także zmniejszyć koszty opracowywania, wdrażania i obsługi rozproszonych systemów zarządzania.

Osiągnięto cel projektu, jakim było modelowanie systemu obsługi portalu gastronomicznego. Dokonano modelowania systemu na podstawie procesów zachodzących w rzeczywistości. Dzięki wdrożeniu systemu można zoptymalizować koszty, poprawić jakość obsługi oraz zautomatyzować procesy dostawy produkcji.

Wdrożenie opracowanego systemu pozwoliło na usprawnienie wymiany informacji między oddzielnymi jednostkami i przejście na elektroniczny system zarządzania. Wdrażanie zmian w systemie spowodowało wzrost konkurencyjności firmy, a funkcjonalność systemu dostosowano do standardów rynkowych.

\section{LITERATURA REFERENCES}

[1] L. Petryshyn, W. Cieslik, M. Petryshyn. Processes Analysis of Networks Management Systems. II International Scientific and Practical Conference "Theoretical and Applied Aspects of Device Development on Microcontrollers and FPGAS” MC\&FPGA-2020: Kharkiv, June 25-26, 2020. - Kharkiv, KhNURE, 2020, Ukraine. In press.

[2] Л. Петришин, Я. Николайчук, Аналитическое моделирование информационных систем автоматизированного управления Analytical modeling of infosystems of automated management. / Lyubomyr Petryshyn // Zarządzanie organizacjami w gospodarce rynkowej: X międzynarodowa naukowa konferencja "Zarządzanie przedsiębiorstwem. Teoria i praktyka": Kraków, 22-23 listopada 2007 r. I pod red. Wiesława Waszkielewicza; - Kraków: Wydawnictwa AGH, 2007. — ISBN 978-83-7464-153-1 - S. 268275. - Bibliogr. s. 338, Abstr.

[3] BP Simulator. [Online]. Available: https://www.bpsimulator.com/run/ july 09, 2019. 